\title{
SEISMIC RESPONSE OF BRIDGE ABUTMENTS ON SURFACE FOUNDATION SUBJECTED TO COLLISION FORCES
}

\author{
Sotiris A. Argyroudis ${ }^{1}$, Stergios A. Mitoulis ${ }^{2}$, and Kyriazis D. Pitilakis ${ }^{3}$ \\ ${ }^{1}$ Aristotle University of Thessaloniki \\ Department of Civil Engineering, P.O.B. 424, 54124, Thessaloniki, GREECE \\ sarg@ civil.auth.gr \\ ${ }^{2}$ University of Surrey \\ Department of Civil and Environmental Engineering, 21AA02, Guildford, GU2 7XH, Surrey, UK \\ s.mitoulis@surrey.ac.uk \\ ${ }^{3}$ Aristotle University of Thessaloniki \\ Department of Civil Engineering, P.O.B. 424, 54124, Thessaloniki, GREECE \\ kpitilak@civil.auth.gr
}

Keywords: Bridge; abutment; embankment; collision force; modeling; Plaxis; SAP 2000; abutment failure modes.

\begin{abstract}
Bridges are important components of the roadway and railway networks, as they must remain operational in the aftermath of the seismic event. Permanent movements of the backwall and the backfill soil and rotational deformations of the abutment-backfill system are well known failure modes that potentially may incite deck unseating mechanisms. However, only a few studies dealt with the modeling of deck-abutment-backfill pounding effect. In this framework, an extended parametric study was conducted on a simplified abutment-backfill analytical model. A typical seat-type abutment was analyzed using 2D nonlinear FE model in Plaxis. Simultaneously, a refined abutment-backfill model was built in commercial software SAP2000 in view to highlight significant parameters of the interaction aiming at identifying the effect of collisions on anticipated damages of the abutment. The assessment of the deckabutment-backfill response was performed on the basis of longitudinal maximum and residual movements and rotations of the abutment that may affect both the integrity and the postearthquake accessibility of the bridge. SSI effects due to the interaction of the deck with the abutment and the backfill soil were considered; analyses showed that large seismic movements during an earthquake and permanent movements of the abutment are deemed to put in danger the abutment itself, the integrity of the end spans and finally the accessibility of the bridge. Comparison of different seat-type abutment models in Plaxis and SAP2000 revealed that modeling of bridge abutments with emphasis on the geotechnical design should be properly made. Poor design assumptions may have a serious impact in the assessment of the response of the abutment-backfill-bridge system.
\end{abstract}




\section{INTRODUCTION}

The earthquake resisting system of bridges mostly relies on the piers and foundations, the isolators and the shear keys. During an earthquake, plastic hinges are expected to be developed at the piers; properly designed isolators intend to increase the fundamental period of the system and dissipate energy through hysteretic behavior. Shear keys are typically used against span unseating. This philosophy seems to be adequately covered by current codes for most of bridge structural elements except the abutments.

However, abutment response, soil-structure interaction and backfill flexibility have been found by post-earthquake reconnaissance reports to significantly influence the response of an entire bridge system under moderate to strong intensity ground motions $[1,2,3,4,5,6,7,8]$. The influence of soil-structure-interaction on the dynamic response of bridges has been recognized [2,9] and has been widely addressed the following years in instrumented bridge overpasses $[10,11]$. The known backfill-abutment-deck interaction constitutes a wide field of study in integral abutment bridges [12] and in bridges with seat-type abutments like the one shown in Figure 1. In the latter case, the backwall of the abutment is typically designed to break free of its base support when is struck by a bridge deck $[13,14]$ mobilizing high values of the passive resistance of the backfill soil $[15,16,17,18]$. The seismic demand and therefore the cost of bridges are strongly influenced by the resistance of the abutment. Hence, refined modelling approaches are necessary in order to reveal the potential mechanisms triggered in the seismic assessment of bridges [4, 5].

Dynamic analysis of highway bridges and modelling of the abutment's capacity is prescribed by various agencies $[13,14,19]$. However, current design practice varies considerably on the use of the abutments as part of the bridge's earthquake resisting system ERS [20]. Simplified force-deflection relationships for modelling embankment-abutment systems were proposed by Sextos et al. [21]. Shamsabadi et al. [22] used mobilized logarithmic-spiral failure surfaces coupled with a modified hyperbolic soil stress-strain behavior -known as LSH soil model- to estimate abutment nonlinear force-displacement capacity as a function of wall displacement and backfill soil properties. The analytical force-displacement expressions were also validated by experimental studies [23].

The seismic response of seat-type abutments and their effect on the integrity of bridges depend on the dynamic resistance and response of the backfill soil and on the capacity and mass of the abutment's structural members (backwall, footing, wingwalls and the approach slab) [7, $24]$. The openings at the expansion joints $[25,26,7,24]$ influence strongly the pounding effects [27] and in turn affect the seismic response of the bridge. However, the post-earthquake condition of abutments has not been studied or evaluated adequately although it is considered to be of vital importance for the bridge to maintain operational and to avoid permanent rotations [24], that would trigger potential primarily damages of the backwall and hence widening of the expansion joints or unfavorable span-unseating mechanisms. In that case, different abutment's design parameters are important: (a) the gap between the deck and the backwall, (b) the mass, the stiffness and the post-earthquake condition of the backwall, (c) the possible overall rotation of the abutment which has been revealed in past earthquakes (Figure 2a), (d) the pre- and post-earthquake condition of the backwall and the backfill (see Figure $2 b$ ) and its relation to the backfilling material. The latter is also influenced by the serviceability and seismic induced settlements, the condition of the approach slab and the wing walls. All these parameters are affecting the performance indicators of the bridge and the selection of appropriate damage states indices (and values) for the construction of fragility curves. 
Recent studies on the seismic fragility of bridges consider the contribution of abutments to the overall bridge system fragility following the common seismic design practices taking into account the activation of the abutment-backfill system due to the gap closure between the deck and the abutments [28, 29]. Argyroudis et al. [30] proposed numerical fragility curves for cantilever bridge abutments on surface foundation considering different soil types, abutment heights and seismic input motions. The performance of the abutment is defined based on the range of the backfill settlement. However, the effect of collision force due to the pounding of the deck to the abutment in the overall system fragility is not considered in these studies.

In this framework, an extended parametric study was conducted and a typical seat-type abutment was modeled and analyzed using 2D nonlinear FE model in Plaxis. Simultaneously, a refined non-linear abutment-backfill model was built in SAP 2000 (ver. 15.0.0) using the validated p-y curves of Plaxis. Modeling accounted for the construction stages of the abutment that modify the initial states of stresses within the backfill soil and the soil pressures on the abutment. A step-by-step analysis-validation procedure was followed, starting from simple static to complex non-linear dynamic models. Comparisons was mainly performed on the basis of horizontal displacement of the abutment's stem and base rotation The properties of the backfill employed in the analyses are based on typical design cases and literature. We selected representative input to cover typical magnitudes, frequency content and duration. SSI effects and the post-impact response of the abutment-backfill were evaluated on the basis of permanent movements and rotations that may affect the bridge's integrity in terms of available seating widths. Potential failure modes of typical seat-type abutments were recognized and qualitatively described when strongly non-linear SSI effects are mobilized due to the interaction of the deck with the abutment and the backfill.

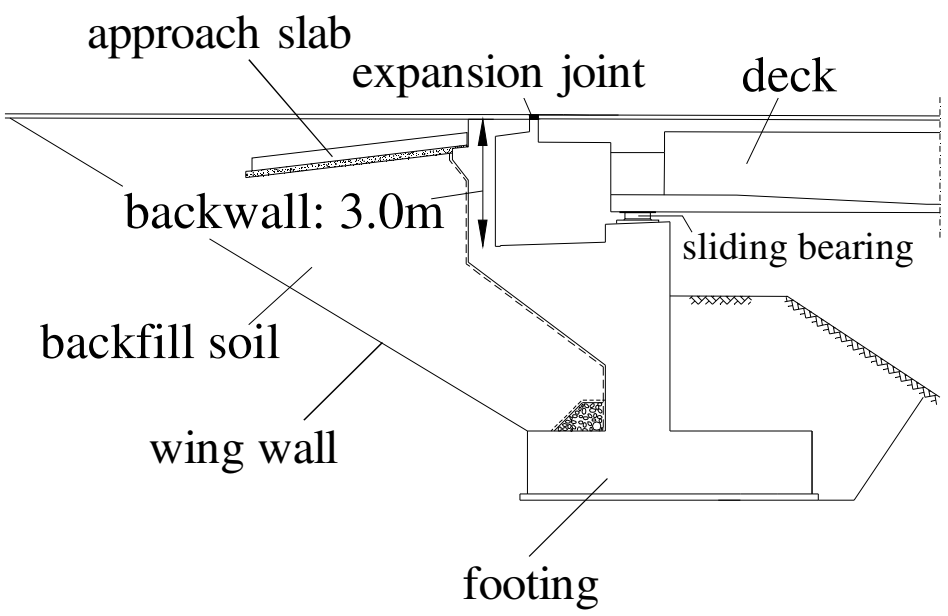

Figure 1: A typical seat type abutment. 


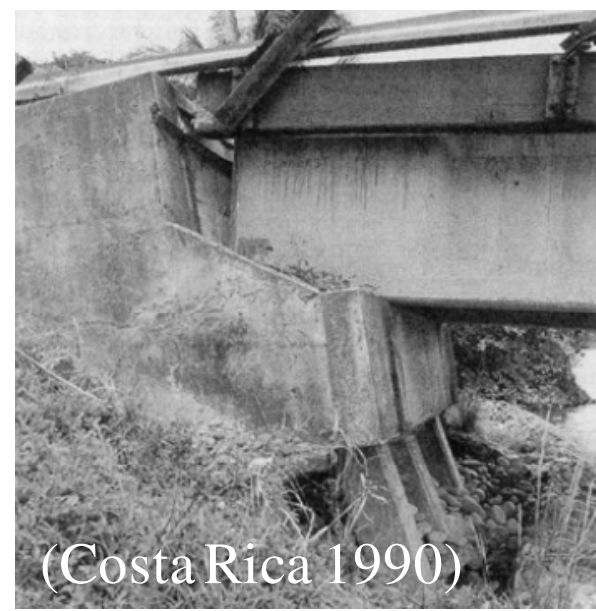

(a)

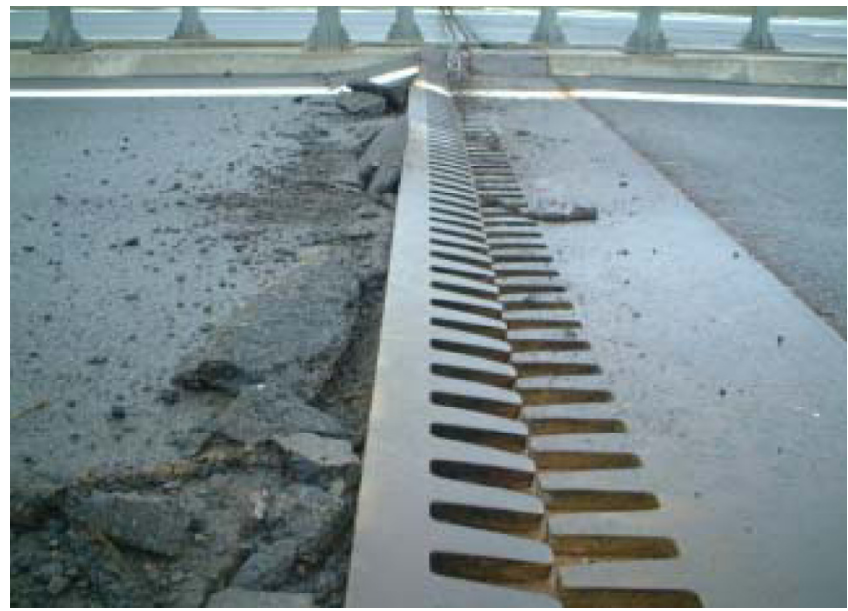

(b)

Figure 2: (a) Rotation of the entire abutment-backfill substructure due to pounding effects (Rio Banano bridge, Costa Rica, 25/3/1990, $\mathrm{M}_{\mathrm{w}}=7.0$ ). (b) Light pounding-induced failure, the expansion joint is damaged but no evidence of large permanent lateral movements is shown.

\section{MODELLING OF ABUTMENT-BACKFILL}

\subsection{Modelling in Plaxis}

The coupled soil-wall interaction analyses were performed with the $2 \mathrm{D}$ (plane strain) finite element code Plaxis (ver. 9.02). Figure 3 describes the model used with a width properly selected to avoid boundary effects. A set of initial analyses is performed to simulate initial geostatic stresses as well as the construction of the wall and the backfill. Then, depending on the validation case, the static or dynamic analyses followed, where the pounding forces are applied at the top of the abutment and the seismic input is applied uniformly at the basis of the model.

Elastic or elasto-plastic soil behavior (i.e. Mohr-Coulomb criterion) is used depending on each case. Proper interface elements with a realistic friction coefficient of $R_{\text {inter }}=0.70$ were used to model the interface behavior between the backfill and foundation soil with the wall, allowing the relative movement between the soil and the abutment. The soil material damping is introduced numerically in the form of Rayleigh damping in case of dynamic analysis.

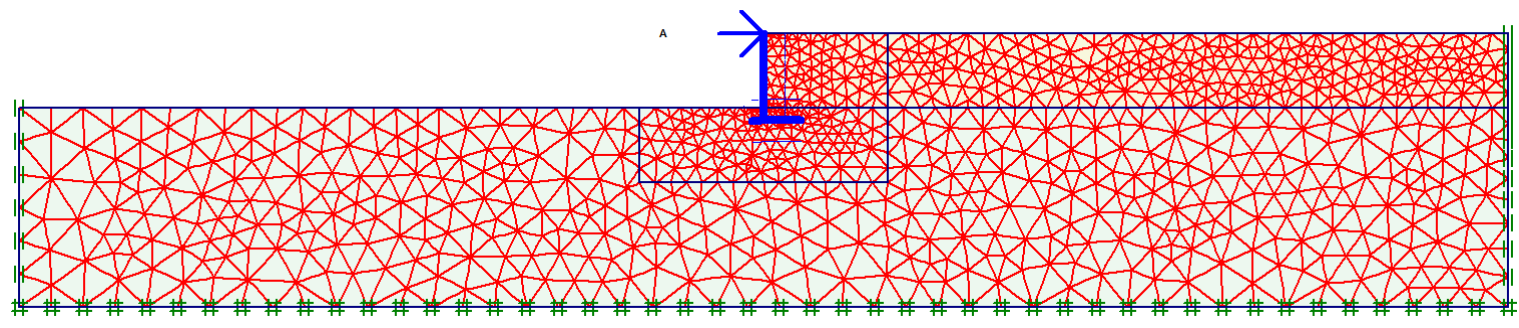

Figure 3: Example of the modeling mesh in Plaxis.

\subsection{Modelling in SAP2000}

Simplified to more complex bridge abutment models were built in SAP 2000 using stick models for the frames and linear or non-linear links for the backfill soil depending on the validation case. Frame sections were used to model the 1-m width of the analyzed abutment- 
backfill system. The objective of this simplified modelling was to provide a step-by-step analysis-validation procedure from simplest to more complex models. This procedure facilitated the validation of the abutment response parameters between the two different simulation approaches employed in the study (SAP 2000 structural model and Plaxis model). This comparison was deemed to be essential as the complex and non-linear response of the abutment under pounding loads is not yet recognized or assessed before. Both models were subjected to longitudinal loading that was compatible to the pounding forces [7]. The time history of the collision forces was induced at the stem (top) of the backwall by the colliding deck. Modeling followed the technique that is described in detail by Mitoulis [7].

Pilot analyses included initially static loading and simulation of backfill's resistance with only linear spring elements attached at both the web of the abutment and the surface foundation of the abutment. Static analyses (Cases 3, 4, 5a, 5b) were performed using linear spring elements that were estimated by the force-displacement diagrams calculated in the Plaxis model. A $0.5 \mathrm{~m}$ at backfill's height discretization was used at this stage to identify both the accuracy offered by potential coarse and dense discretization grids and to estimate the critical height of the backfill soil that participated strongly to the modeled impacts, as it was evident that not the entire height of the backfill soil resists to this effect. Linear and non-linear link elements with hysteretic behavior were used to model the response of the backfill soil under dynamic deck-to-abutment collision force that was introduced in models 6 and 7 (see Figures 6 and 9). The multi-linear plastic with kinematic hysteretic model of SAP2000 was used (case 7, Figure 9). The model was chosen to match the response of the SAP model with the Plaxisproduced hysteresis loops of the backfill soil under pounding loading. The procedure introduced the analysis of Plaxis' abutment-backfill model and the outcomes were utilized to decide on the load-dependent non-linear p-y curves with zero tension resistance and a hysteretic response under compression for the SAP-model. Modelling of the backfill soil was performed at the upper $3 \mathrm{~m}$ due to two reasons. Firstly, it was recognized that the accuracy of the model is not influenced strongly by the abutment-backfill translational resistance of the lower part. Secondly, the p-y relations at very low backfill's deflections that were observed at lower soil layers are not reliable to be used for the estimation of non-linear properties of links used at SAP 2000. Besides, the comparison of the two models showed a good agreement between SAP and Plaxis, namely the simplified and the rigorous model. Thus, modelling of the abutment was made by frame elements that are properly account for the stiffness of the backwall. The observed discrepancy in the computed longitudinal movements $\left(\mathrm{U}_{\mathrm{x}}\right)$ between the two models was deemed satisfactory in case of linear soil behavior. However, when a non-linear behavior is introduced (case 7) the results present considerable differences which are attributed to particular differences of the two models.

\section{COMPARISON OF THE TWO MODELS (SAP2000 AND PLAXIS)}

\subsection{Collision force as a static loading}

The following cases ( 1 to 5) are examined (Figure 4). The analysis was performed assuming an elastic behavior of the soil. We compare the results of the two models on the basis of the computed horizontal displacement on the top of the abutment and the developed stresses of the abutment (M, N, Q diagrams).

\section{Case 1}

The foundation of the abutment is assumed on rock and is considered as restrained. The rock has volumetric weight $\gamma=24 \mathrm{kN} / \mathrm{m}^{3}$, Young's modulus $\mathrm{E}=2.0 \mathrm{E}+08 \mathrm{kN} / \mathrm{m}^{2}$ and Poisson's ratio $\mathrm{v}=0.3$. A horizontal force equal to $1000 \mathrm{kN}$ is applied on the top of the abutment. Initially, the structural response of the abutment was compared to the one of the SAP2000 
model. The comparison incorporated the concrete part of the abutment-system only (i.e. a zero resistance backfill was used) to represent the first stage of construction. A very good agreement between Plaxis $(27 \mathrm{~mm})$ and SAP $(26 \mathrm{~mm})$ models is observed. The theoretical value is $28.85 \mathrm{~mm}$ accounting for both the flexural and shear deflection at fixed based cantilever.

Case 2

Same as case 1; however rotation is now allowed at the abutment base. The comparison of the two models is again satisfactory. In case of Plaxis model, rock exhibited slight base rotations that were translated into longitudinal abutment movements at its top. Hence, the SAP model responded with smaller rotations.

\section{Case 3}

The foundation of the abutment is assumed again on rock and the backfill soil is considered with volumetric weight $\gamma=18 \mathrm{kN} / \mathrm{m}^{3}$, Young's modulus $\mathrm{E}=2.5 \mathrm{E}+05 \mathrm{kN} / \mathrm{m}^{2}$ and Poisson's ratio $\mathrm{v}=0.499$. As previously a horizontal force equal to $1000 \mathrm{kN}$ is applied on the top of the abutment. The backfill in SAP is modeled through static springs, which are estimated based on the response of the backfill in the Plaxis model. In particular, the variation of static stiffness $\left(\mathrm{k}_{\mathrm{x}}\right)$ with depth is estimated based on the variation of horizontal displacements and stresses in the interface between the abutment wall and the backfill. The corresponding spring constants are calculated every $0.5 \mathrm{~m}$ of the wall by fitting a polynomial function in the displacements' and stresses' profiles.

A good agreement between Plaxis $(9.3 \mathrm{~mm})$ and SAP $(10.3 \mathrm{~mm})$ models is observed when the horizontal displacements on the top of the abutment are compared. As expected the displacement is lower than case 2 due to the resistance of the backfill. If a fixed base is considered, the SAP model gives a displacement equal to $9.9 \mathrm{~mm}$, which is even closer to the Plaxis results.

\section{Case 4}

The same model as in case 3, but the force here has different direction towards the deck and is again equal to $100 \mathrm{kN} / \mathrm{m}$. The comparison of the two models is satisfactory. The response of the wall is almost the same with a free cantilever. In case of Plaxis model, the backfill abutment resistance due to friction reduces up to $4.5 \%$ the movement of the wall. If a restrained base is considered, then the displacement on the top is equal to $-2.29 \mathrm{~mm}$ and -2.94 $\mathrm{mm}$ in Plaxis and SAP model respectively.

\section{Case 5}

The abutment is now founded on soil with volumetric weight $\gamma=18 \mathrm{kN} / \mathrm{m}^{3}$, Young's modulus $\mathrm{E}=5.0 \mathrm{E}+05 \mathrm{kN} / \mathrm{m}^{2}$ and Poisson's ratio $\mathrm{v}=0.499$. The spring constants are evaluated for the backfill and the foundation soil, following the same procedure as described in case 3. Depending on the type of loading, different parts of the foundation soil are activated. Two types of forces are applied, $1000 \mathrm{kN} / \mathrm{m}$ towards the backfill (case $5 \mathrm{a}$ ) and $100 \mathrm{kN} / \mathrm{m}$ in the opposite deck direction (case $5 b$ ).

In case 5a the comparison is satisfactory; a displacement of $13 \mathrm{~mm}$ was calculated with the Plaxis model, while $12.2 \mathrm{~mm}$ movement was calculated with SAP model.

In case of a compliant foundation (case 5b), the outward displacement at the top of the wall $(\sim 5 \mathrm{~mm})$ is due to the bending motion of the wall $(3 \mathrm{~mm})$ and the rotation of the foundation (another $2 \mathrm{~mm}$ ). In Plaxis model the effect of the friction between the backfill and the wall results to lower total displacement (about $20 \%$ of difference). When a fixed base model was considered for the abutment for case $5 \mathrm{~b}$, then the displacement at abutment's top was found equal to $2.60 \mathrm{~mm}$ and $2.94 \mathrm{~mm}$ in Plaxis and SAP model respectively. 
Differences between the two models in terms of $M_{\max }$ and $U_{x}$ reflect the fact that the SAP FEM model cannot capture completely the developed soil pressures on the abutment wall, compared to Plaxis were obviously active and passive pressures were better captured.

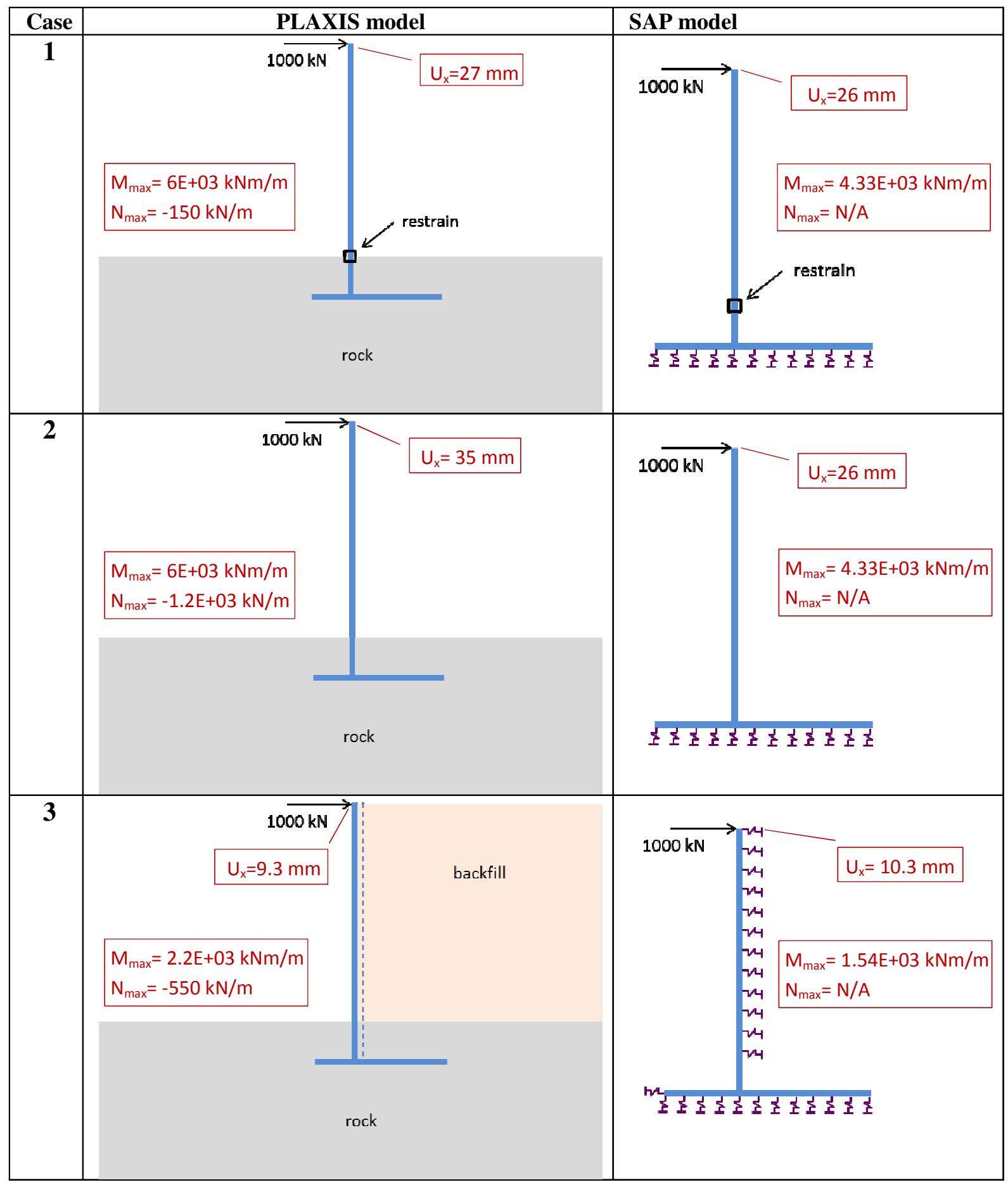

Figure 4: Cases 1 to 5: Static horizontal loading on top of the abutment. Comparison between Plaxis and SAP. Displacement at the top of the abutment, bending moments and axial forces. 


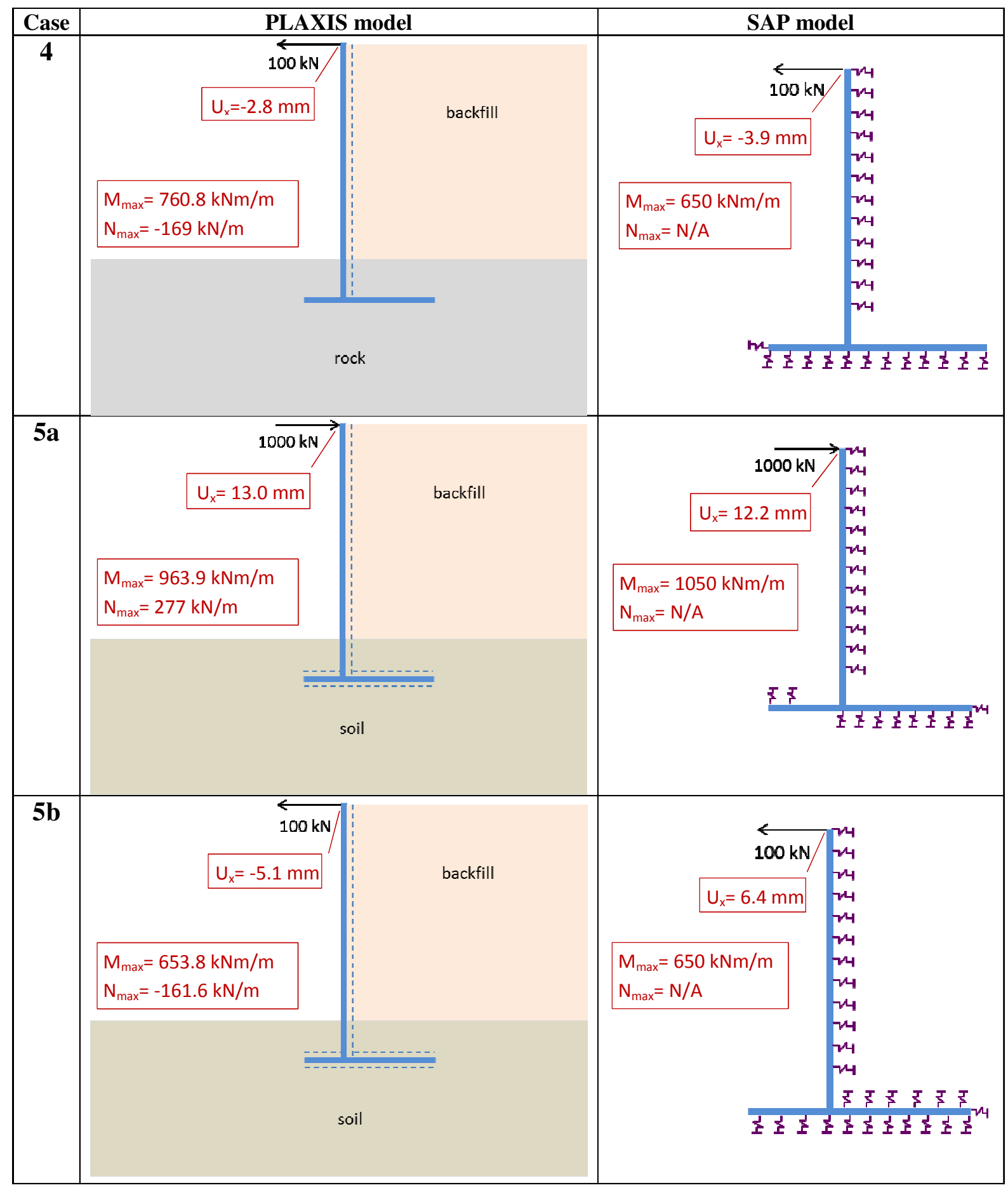

Figure 4: Cases 1 -5: Static horizontal loading on top of the abutment. Comparison between Plaxis and SAP. Displacement at the top of the abutment, bending moments and axial forces (continued).

\subsection{Collision force as a simplified dynamic loading}

Pounding is a geometrically non-linear dynamic effect. Most of bridge engineers are familiar with the effect mostly by identifying post-earthquake local damages to bridge deck slabs and abutments, rather than from analytical and theoretical approaches [25, 27]. Current state of practice introduced several structural schemes to mitigate pounding effects and its consequences on bridges, such as elastomeric pads interjecting between colliding elements. Such measures are expected to reduce effectively pounding force magnitudes [31]. In the following 
cases (Figures 5, 6, 8), the deck-to-abutment collision is modeled through 4 different simplified input motions with variable durations ranging from $0.35 \mathrm{~s}$ to $3.5 \mathrm{~s}$ and frequencies ranging from 1 to $10 \mathrm{~Hz}$. Based on analytical results [7], the maximum positive force towards the abutment-backfill was up to $1000 \mathrm{kN} / \mathrm{m}$, i.e. $1000 \mathrm{kN}$ per meter in the transverse direction of the abutment. The negative force (towards the deck) reaches $150 \mathrm{kN} / \mathrm{m}$, based on typical bearings' resistance that is activated when the deck is drawn away from the abutment. The frequencies of the input motion have been selected in accordance to the fundamental period of the abutment-backfill system that was found to be at the order of $0.25 \mathrm{~s}$.

The following periods $(\mathrm{T})$ and durations $(\mathrm{t})$ of the motion are considered: a) $\mathrm{T}=0.10 \mathrm{~s}$, $\mathrm{t}=0.35 \mathrm{~s}$; b) $\mathrm{T}=0.25 \mathrm{~s}, \mathrm{t}=0.875 \mathrm{~s}$; c) $\mathrm{T}=0.50 \mathrm{~s}, \mathrm{t}=1.75 \mathrm{~s}$; d) $\mathrm{T}=1.00 \mathrm{~s}, \mathrm{t}=3.50 \mathrm{~s}$.

\section{Case 6}

Analyses were performed considering that the soil behavior is linear (Figures 5, 6). The stiffness values estimated in previous case 5 were applied to model the foundation soil. The spring values for the backfill are estimated from the Plaxis model results. In particular, using two values of the resulting Plaxis p-y curve, linearization of the $p$-y curve was performed. The two p-y set of values were obtained as follows: one at the time when the abutment is at its original position (i.e. when displacement equals zero) and one at the moment when the abutment reaches its maximum displacement, i.e. when the force towards the backfill equals 1000 $\mathrm{kN} / \mathrm{m}$.

As an example, Figure 7 illustrates the response of the abutment for case $6 \mathrm{c}(\mathrm{T}=0.50 \mathrm{~s})$. The time window captured abutment's response between $t=0.82 \mathrm{~s} \quad\left(\mathrm{U}_{\mathrm{x}}=0 \mathrm{~mm}\right)$ and $\mathrm{t}=1.26 \mathrm{~s}$ $\left(\mathrm{U}_{\mathrm{x}}=13.3 \mathrm{~mm}\right)$. The same figure shows the displacement computed with SAP model. In this model the springs that have been estimated from the Plaxis model as described before are applied. A good agreement is observed for the peak values of positive displacements, which corresponds to the maximum applied forces towards the backfill. The difference between the two models for $\mathrm{t}=0.70-1.0 \mathrm{~s}$, and beyond $\mathrm{t}=1.45 \mathrm{~s}$ is due to the resistance of the backfill to the lower part of the abutment in Plaxis model, when the force towards the deck is applied.

In Table 1 the displacements at the top of the abutment at the end of the analysis and the maximum values of M, N, Q are reported, showing a good agreement between the two models.



Figure 5: Case 6 and 7 in Plaxis model. The deck-to-abutment collision is applied as time history with different frequency and duration. The soil behavior is assumed to be elastic (Case 6) or elasto-plastic (Case 7). 




Figure 6: Case 6 in SAP model. The deck-to-abutment collision is applied as time history with different frequency and duration. The backfill and foundation soil is modeled with static springs.



Figure 7: Comparison of estimated displacement at the top of the abutment from Plaxis and SAP models for case $6 \mathrm{c}(\mathrm{T}=0.5 \mathrm{~s})$.

\section{Case 7}

Following the modeling process in case 6 , the backfill soil now is modeled by an elastoplastic soil behavior obeying the Mohr-Coulomb criterion. In this case, the springs on the wall of SAP model follow a bi-linear behavior (Figure 9) with the upper $3.0 \mathrm{~m}$ of the backfill considered as crucial for the abutment behavior (see \$2.2). The bi-linear behavior is defined based on the relation between force $\left(F_{x}\right)$ and displacement $\left(U_{x}\right)$ for the loading between $F_{x}=0$ and $F_{x}=1000 \mathrm{kN}$ of the previously (case 6) applied input motions.

The variation of displacement is estimated from the Plaxis model in the interface between the $6 \mathrm{~m}$ high wall and the backfill for the corresponding force steps and for the upper $3.0 \mathrm{~m}$ of the structure (i.e. from depth $-3 \mathrm{~m}$ up to the surface of the backfill soil). Figure 8 shows an example of the deformed abutment-backfill model and the variation of displacement in the interface with applied force at the surface of backfill (i.e. top of the abutment). A bi-linear curve is 
then fitted to each $\mathrm{F}_{\mathrm{x}}-\mathrm{U}_{\mathrm{x}}$ curves in order to describe the behavior of the springs in SAP model (Figure 9).

The frequency (period) of the applied collision force has an important effect as it is shown in Figure 8. In particular, the estimated displacements are increasing when the frequency of the input force is decreasing. In Table 1 the displacements at the top of the abutment at the end of the analysis (residual) and the maximum values of $\mathrm{M}, \mathrm{N}, \mathrm{Q}$ during the analysis are reported for the input force with $\mathrm{T}=0.1 \mathrm{~s}(10 \mathrm{~Hz})$ and $\mathrm{T}=0.5 \mathrm{~s}(2 \mathrm{~Hz})$. The observed differences are attributed to the non-linear soil behavior and SSI effects, which are not modeled in the same way in the two models. In particular, in SAP only the upper $3 \mathrm{~m}$ of the backfill are modeled through the corresponding springs while the mass of the backfill is not considered and the pressure of the backfill towards the wall and the friction between the wall and the backfill are also not accounted as it happens in Plaxis. Finally, in case 7, the foundation soil is modeled through linear springs, while an elasto-plastic behavior is assumed in Plaxis model.


Figure 8: Deformed abutment-backfill model and computed displacements at the top of the abutment-backfill interface for applied collision force $\mathrm{F}$ (from 0 to $1000 \mathrm{kN}$ ) with different periods (frequencies). 


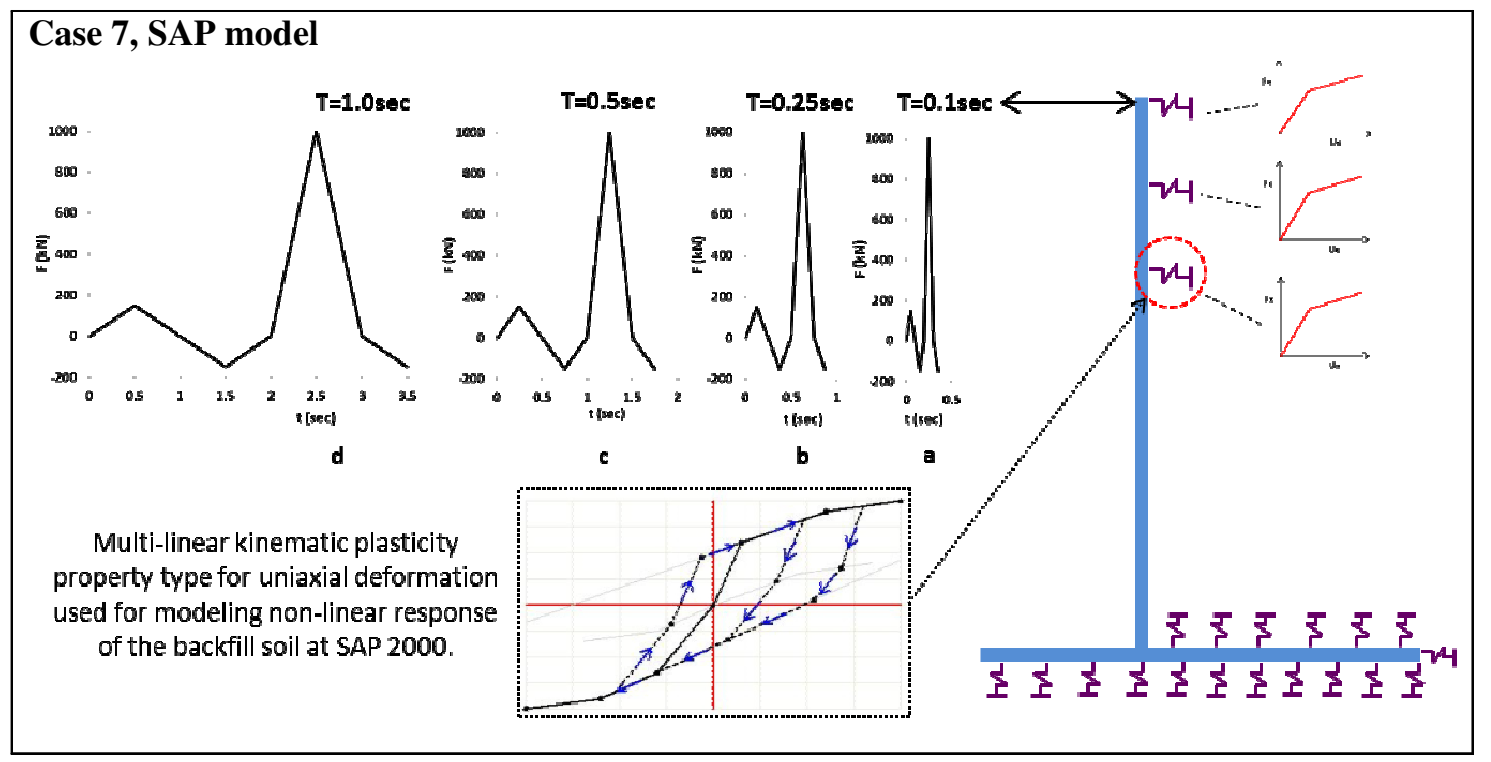

Figure 9: Case 7 in SAP model. Time histories of the deck-to-abutment collision for different frequency, duration and non-linear soil behavior. The backfill is modeled with bi-linear springs.

\begin{tabular}{|c|c|c|c|c|}
\hline model & $\begin{array}{l}\max U_{x} \text { (top) } \\
(\mathrm{mm})\end{array}$ & $\begin{array}{l}\max M \\
(\mathrm{kNm} / \mathrm{m})\end{array}$ & $\begin{array}{l}\max N \\
(\mathrm{kN} / \mathrm{m})\end{array}$ & $\begin{array}{l}\max Q \\
(\mathrm{kN} / \mathrm{m})\end{array}$ \\
\hline case $6, \mathrm{~T}=0.1 \mathrm{sec}$ (Plaxis) & 11.6 & -1440 & 391.6 & 998.5 \\
\hline case $6, \mathrm{~T}=0.1 \mathrm{sec}(\mathrm{SAP})$ & 9.6 & -1199 & N/A & 232.4 \\
\hline case $6, T=0.5 \sec ($ Plaxis $)$ & 8.5 & -1010 & 350 & 998.5 \\
\hline case $6, \mathrm{~T}=0.5 \mathrm{sec}(\mathrm{SAP})$ & 9.5 & -968.8 & N/A & 157 \\
\hline case $7, \mathrm{~T}=0.1 \mathrm{sec}$ (Plaxis) & 27.5 & -1850 & 364.6 & 999.8 \\
\hline case $7, \mathrm{~T}=0.1 \mathrm{sec}(\mathrm{SAP})$ & 1.0 & -582.6 & N/A & 86.6 \\
\hline case $7, \mathrm{~T}=0.5 \mathrm{sec}$ (Plaxis) & 383.7 & -2070 & 279.8 & 999.8 \\
\hline case $7, \mathrm{~T}=0.5 \mathrm{sec}(\mathrm{SAP})$ & 268.5 & -2929 & N/A & 385.1 \\
\hline
\end{tabular}

Table 1: Displacement at the top of abutment at the end of analysis and maximum values of M, N, Q during the analysis.

\section{DYNAMIC MODELLING OF SEISMIC INPUT AND COLLISION FORCE}

\section{Case 8}

A full dynamic analysis is performed in Plaxis, considering both the deck-to-abutment collision and the seismic motion at the bedrock with real time histories (Figure 10). In particular, the deck-to-abutment pounding time history is applied on the top of the abutment wall (Figure 11b). Further details can be found in a previous analytical study [7] that was conducted utilizing real bridges with seat-type abutments. The seismic input is applied uniformly at the basis of the model using the record of Figure 11a. The properties of the soil and backfill are given in Table 2.

The basis of the model was assumed to be rigid. The total width of the model is $420 \mathrm{~m}$, which is sufficient to avoid boundary effects considering that absorbent boundaries were also used at the lateral boundaries. The domain was discretised with 3822 15-node plain strain triangular elements. In the area around the abutment wall the mesh was refined as shown in Fig- 
ure 10. The soil behavior follows the Mohr-Coulomb criterion. Proper interface elements with a realistic friction coefficient of $R_{\text {inter }}=0.70$ were again used to model the interface between the backfill and foundation soil with the wall.

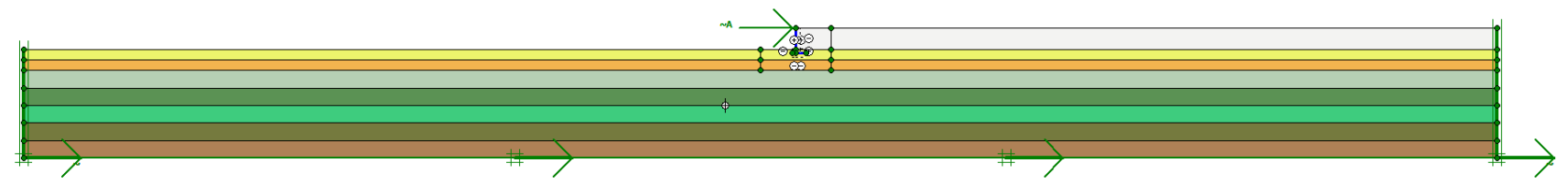

soil-abutment-backfill model

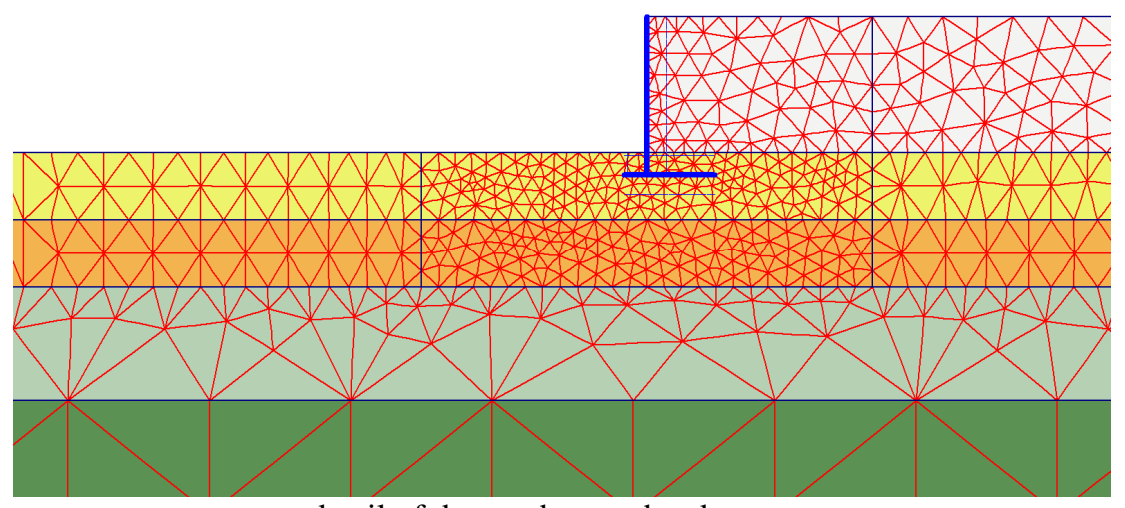

detail of the mesh near the abutment

Figure 10: Case 8 in Plaxis model. The deck-to-abutment collision is given as time history and a seismic input motion is applied in the basis of the model.



(a)

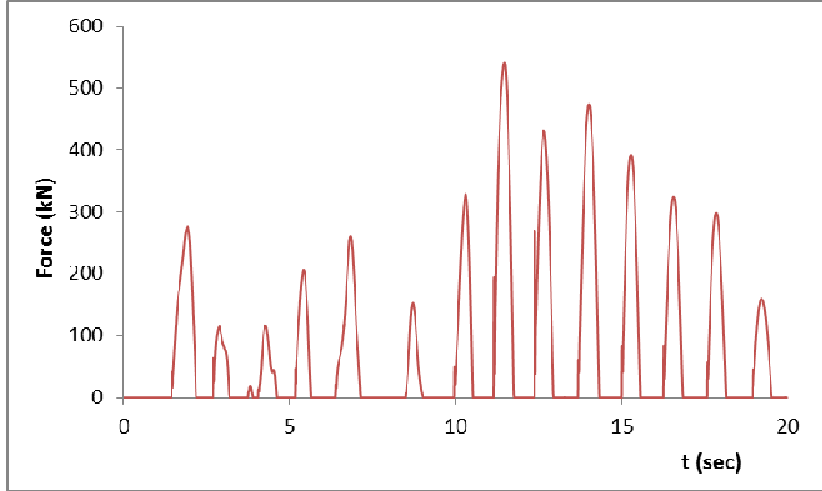

(b)

Figure 11: Seismic input (a) and collision force (b) applied in the full dynamic analysis with Plaxis. 


\begin{tabular}{lllllll}
\hline Layer & Depth $(\mathrm{m})$ & $\gamma$ & $\mathrm{E}\left(\mathrm{kN} / \mathrm{m}^{2}\right)$ & $\mathrm{c}\left(\mathrm{kN} / \mathrm{m}^{2}\right)$ & $\varphi\left(^{0}\right)$ & $\mathrm{v}$ \\
\hline backfill & $0-6$ & 18.0 & $3.260 \mathrm{E}+04$ & 0.01 & 36 & 0.30 \\
1 & $0-3$ & 19.0 & $9.378 \mathrm{E}+04$ & 50.0 & 0 & 0.35 \\
2 & $3-6$ & 19.0 & $9.378 \mathrm{E}+04$ & 73.8 & 0 & 0.35 \\
3 & $6-11$ & 19.0 & $1.825 \mathrm{E}+05$ & 92.0 & 0 & 0.35 \\
4 & $11-16$ & 19.0 & $2.269 \mathrm{E}+05$ & 115.0 & 0 & 0.35 \\
5 & $16-21$ & 19.0 & $2.722 \mathrm{E}+05$ & 139.0 & 0 & 0.35 \\
6 & $21-26$ & 19.0 & $3.173 \mathrm{E}+05$ & 168.8 & 0 & 0.35 \\
7 & $26-31$ & 19.5 & $3.708 \mathrm{E}+05$ & 192.5 & 0 & 0.35 \\
\hline
\end{tabular}

Table 2: Properties of soil and backfill

An example of the analysis output is given in Figures 12 and 13 where the vertical and horizontal displacements of the backfill as well as the deformed mesh are illustrated. The maximum permanent displacements reach about $34.2 \mathrm{~cm}$ in the horizontal and $4.3 \mathrm{~cm}$ in the vertical direction of the backfill. It is noted that the approach slab and the wing walls of the abutment, which would improve the overall performance of the abutment-backfill system, are not considered in the analysis, as the objective of the present study is the preliminary estimation of the abutment performance considering the soil-abutment-backfill interaction under collision forces and seismic motion. The role of this interaction is important for the identification of failure modes and therefore for the vulnerability assessment of bridges.

Despite the simplifications considered in this study, it can be underlined that the calculated response of the abutment-backfill system is found to be significant in both the response and the post-impact and post-earthquake performance of the bridge. Firstly, the computed abutment maximum lateral displacement in the longitudinal direction of the bridge is large enough to put in question the support of the deck. Seating width of the order of $450 \mathrm{~mm}$ to $600 \mathrm{~mm}$ required in Eurocode [32] (referred to as overlap length) and Caltrans [14] respectively may not be sufficient. Moreover, we must notice that the permanent deflection of the backwall, which may occur when the deck pounds onto the backwall, is not considered in these provisions. Additionally, the post-earthquake residual displacements of the abutment, which was found equal to $262 \mathrm{~mm}$ in our case (see Figure 13) is deemed to be critical, as bridges are expected to be accessible for emergency transportation. Hence, adequate measures must be taken for the abutment and the backfill to ensure the post-earthquake emergency traffic. Last but not least, the computed vertical movement of the abutment $(43 \mathrm{~mm}$, Figure $12 \mathrm{a})$ is considered quite large at least for box girder bridges, constructed by either the incremental launching method or the balanced cantilever method. Prestressed box-girder decks are not allowed to be cracked under seismic loading. This is required in order to preserve the durability of the tendons. Hence, a $43 \mathrm{~mm}$ vertical movement of the abutment may trigger secondary effects that will reflect on the durability of the bridge. Such issues should not be overlooked under the seismic design philosophy that introduces the "controllable failure mode" philosophy. 

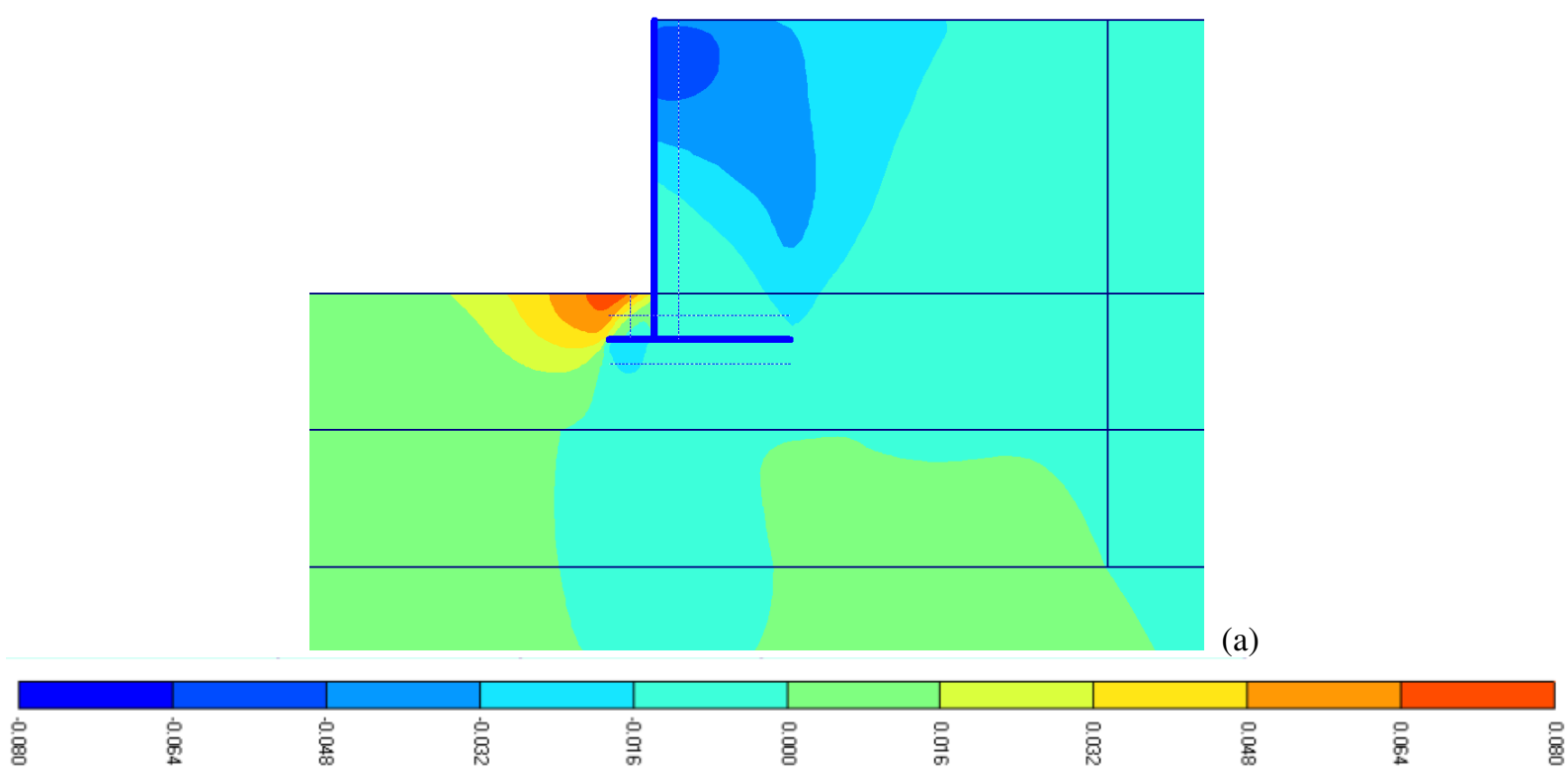

[m]

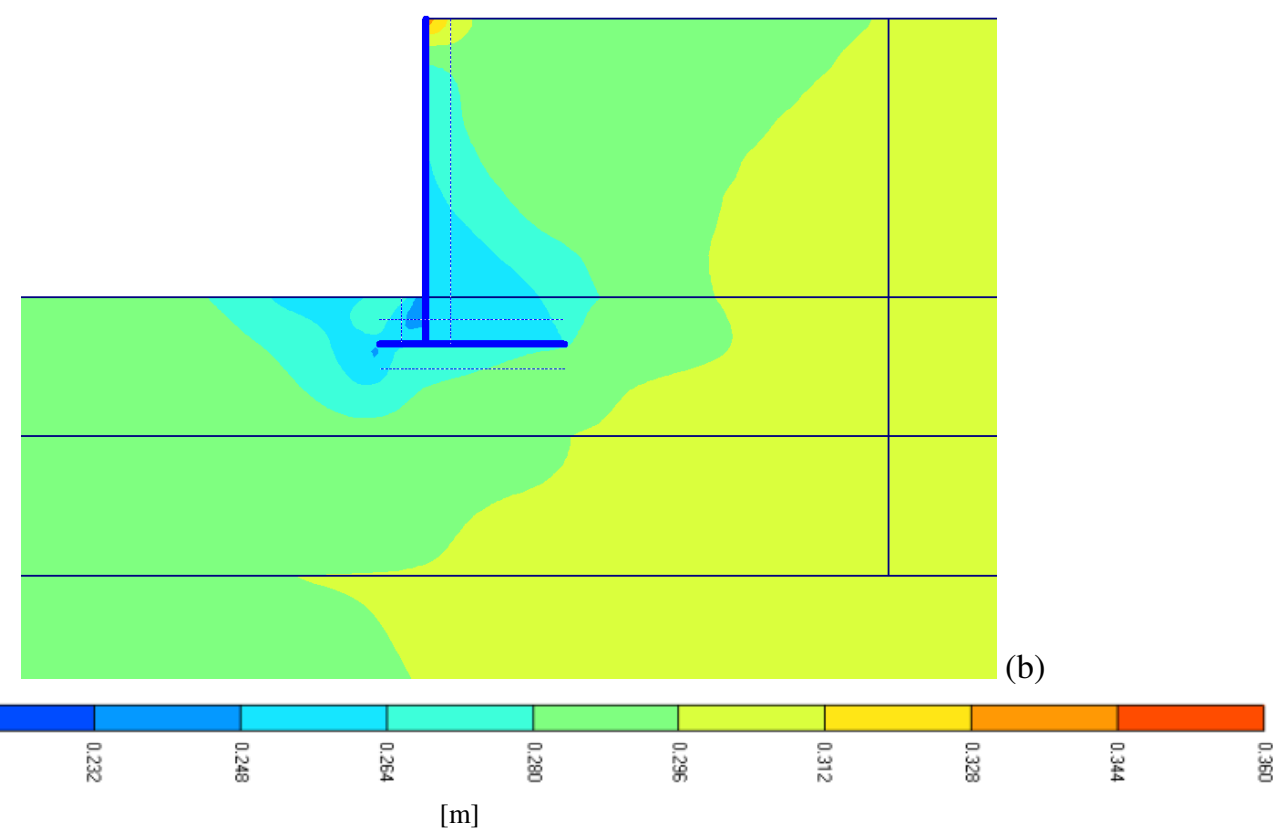

Figure 12: Distribution of the backfill permanent (a) vertical (max 43mm) and (b) horizontal (max $342 \mathrm{~mm})$ displacements 


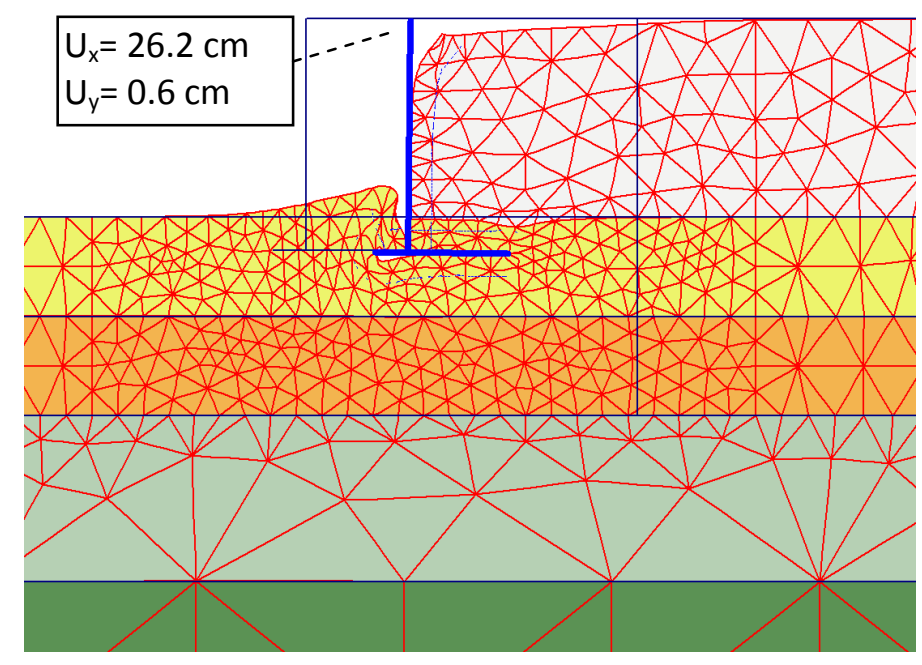

Figure 13: Deformed mesh of the abutment-backfill model and maximum permenant displacements of the abutment

\section{CONCLUSIONS}

A typical seat-type abutment was analyzed using 2D FE model in Plaxis and SAP2000. The SAP model is compared to the Plaxis results considering the interaction between abutment and backfill under static and dynamic deck-to-abutment collision forces. In particular, the variation of estimated displacements in the abutment-backfill interface with Plaxis model is used for the definition of spring properties that are used to model the backfill behavior in the SAP model.

In case of elastic soil behavior and static input forces the agreement between the two models is satisfactory. When a simplified dynamic loading is imposed under the assumption of linear soil behavior the agreement between the two models is good in terms of peak values of displacements. When a non-linear soil behavior is introduced, the soil springs follow a bilinear behavior. Observed differences between the two models are attributed to the fact that the SAP model cannot capture the "passive" soil pressures towards the abutment, while both active and passive pressures were captured with the Plaxis FEM model.

Finally, a full dynamic analysis is performed under both real collision and seismic motion. A preliminary identification of failure modes considering the collision forces as well as the seismic motion is made. The residual horizontal and vertical displacements of the backfill together with the inward or outward rotation of the abutment are critical features for the accessibility of the bridge in the emergency period just after the earthquake event. Therefore these failure modes should be clearly identified and quantified for the definition of damage states in an integrated vulnerability analysis of bridges and abutments. It is pointed out that both the maximum and the permanent post-earthquake longitudinal abutment movement may trigger unseating mechanisms and emergency traffic disruption respectively. Observed vertical abutment seismic movements may cause cracking to the deck, especially for bridges with stiffer box-girder prestressed continuous superstructures, in which cracking may reduce rapidly the life of the tendons and therefore to cause significant long term effects.

To generalize this observation through a comprehensive parametric analyses it is necessary to accurately model the non-linear soil behavior and most important, to capture the SSI effects, and to model the structure-backfill interface behavior in a way the soil pressures and gap phenomena could be reproduced accurately 


\section{REFERENCES}

[1] A. Aviram, K.R. Mackie, B. Stojadinovic, Effect of abutment modeling on the seismic response of bridge structures. Earthquake Engineering and Engineering Vibration; 7 (4): 395-402, 2008.

[2] R.K. Goel, A. Chopra. Evaluation of bridge abutment capacity and stiffness during earthquakes. Earthquake Spectra; 13(1): 1-23, 1997.

[3] M. Inel, M.A. Aschheim, Seismic Design of Columns of Short Bridges Accounting for Embankment Flexibility. ASCE Journal of Structural Engineering; 130(10): 1515-1528, 2004.

[4] A.J. Kappos, P. Potikas, A.G. Sextos. Seismic assessment of an overpass bridge accounting for non-linear material and soil response and varying boundary conditions, ECCOMAS Thematic Conference on Computational Methods in Structural Dynamics and Earthquake Engineering, Crete, Greece, 2007.

[5] A.J. Kappos, A.G. Sextos, Seismic assessment of bridges accounting for nonlinear material and soil response, and varying boundary conditions. NATO Science for Peace and Security Series C: Environmental Security, 2009, III, 195-208, DOI: 10.1007/978-90481-2697-2_15, 2009.

[6] A. Kotsoglou, S. Pantazopoulou, Response simulation and seismic assessment of highway overcrossings. Earthquake Engineering \& Structural Dynamics; 39 (9): 991-1013, 2010 .

[7] S.A. Mitoulis, Seismic design of bridges with the participation of seat-type abutments, Engineering Structures, 44: 222-233, 2012.

[8] A. Mwafy, A. Elnashai, W.H. Yen, Implications of Design Assumptions on Capacity Estimates and Demand Predictions of Multispan Curved Bridges. ASCE Journal of Bridge Engineering; 12 (6): 710-726, 2007.

[9] K. Mackie, B. Stojadinovic. Bridge Abutment Model Sensitivity for Probabilistic Seismic demand evaluation, Proceedings of the 3rd National Seismic Conference \& Workshop on Bridges \& Highways, April 28-May 1, 2002. Portland, 2002.

[10] J. Zhang, N. Makris, Kinematic response functions and dynamic stiffnesses of bridge embankments. Earthquake Engineering and Structural Dynamics; 31 (11): 1933-1966, 2002 .

[11] M. Inel, M.A. Aschheim, Seismic Design of Columns of Short Bridges Accounting for Embankment Flexibility. ASCE Journal of Structural Engineering; 130(10): 1515-1528, 2004.

[12] M. Dicleli, Integral Abutment-Backfill Behavior on Sand Soil-Pushover Analysis Approach. ASCE Journal of Bridge Engineering; 10(3), 354-364, 2005.

[13] AASHTO HB-17, Standard Specifications for Highway Bridges, 17th Edition American Association of State and Highway Transportation Officials, 2002.

[14] CalTrans, Seismic Design Criteria, Version 1.6. California Department of Transportation, Sacremento, CA, 2010. 
[15] A. Lemnitzer, E.R. Ahlberg, R.L. Nigbor, A. Shamsabadi, J.W. Wallace, J.P. Stewart. Lateral Performance of Full-Scale Bridge Abutment Wall with Granular Backfill. ASCE Journal of Geotechnical and Geoenvironmental Engineering; 135(4), 2009.

[16] R. Siddharthan, M. El-Gamal, E.A. Maragakis, Nonlinear bridge abutment stiffnesses: Formulation verification and design curves. NDOT Research Report: RDT95-012, 2001.

[17] P. Wilson and A. Elgamal, Bridge-abutment-backfill dynamic interaction modeling based on full scale tests. Proceedings of the 9th U.S. National and 10th Canadian Conference on Earthquake Engineering; Paper No 777, Toronto, Canada, 2010.

[18] P. Wilson and A. Elgamal, Full-Scale Bridge Abutment Passive Earth Pressure Experiment and Simulation. ASCE Journal of Geotechnical and Geoenvironmental Engineering, 136(12): 1634-1643, (2010).

[19] EN 1997-1 Eurocode 7: Geotechnical design - Part 1: General rules, 2004.

[20] NCHRP 472, Comprehensive Specification for the Seismic Design of Bridges, National Cooperative Highway Research Program, Transportation Research Board, ATC/MCEER Joint Venture Redwood City, CA and Buffalo, NY, 2002.

[21] A. Sextos, K. Mackie, B. Stojadinovic, O. Taskari, Simplified P-y relationships for modelling embankment abutment systems of typical California bridges, 14th World Conference on Earthquake Engineering, Beijing, China, 2008.

[22] A. Shamsabadi, K.M. Rollins, M. Kapuskar, Nonlinear Soil-Abutment-Bridge Structure Interaction for Seismic Performance-Based Design. ASCE Journal of Geotechnical and Geoenvironmental Engineering; 133 (6): 707-720, 2007.

[23] A. Shamsabadi, P.K. Tehrani, J.P. Stewart, E. Taciroglu, Validated Simulation Models for Lateral Response of Bridge Abutments with Typical Backfills. ASCE Journal of Bridge Engineering; 15 (3): 302-311, 2010.

[24] J.P. Moehle, M.O. Eberhard, Earthquake damage to bridges. Bridge Engineering Handbook. Ed. Wai-Fah Chen and Lian Duan Boca Raton: CRC Press, 2000.

[25] R. Jankowski, K. Wilde and Y. Fujino. Pounding of superstructure segments in isolated elevated bridge during earthquakes. Earthquake Engineering \& Structural Dynamics; 27(5): 487-502, 1998.

[26] R. Jankowski, K. Wilde and Y. Fujino. Reduction of pounding effects in elevated bridges during earthquakes. Earthquake Engineering \& Structural Dynamics; 29(2): 195-212, 2000 .

[27] S.A. Anagnostopoulos, Equivalent viscous damping for modeling inelastic impacts in earthquake pounding problems. Earthquake Engineering and Structural Dynamics; 33 (8): 897-902, 2004.

[28] B.G. Nielson, R. DesRoches, Seismic fragility methodology for highway bridges using a component level approach. Earthquake Engineering Structural Dynamics 36(6), 823839, 2007.

[29] I.F. Moschonas, A.J. Kappos, P. Panetsos, V. Papadopoulos, T. Makarios, P. Thanopoulos, Seismic fragility curves for greek bridges: methodology and case studies. Bulletin of Earthquake Engineering 7(2), 439-468, 2009. 
[30] S. Argyroudis, A.M. Kaynia, K. Pitilakis, Development of fragility functions for geotechnical constructions: application to cantilever retaining walls. Soil Dynamics and Earthquake Engineering, http://dx.doi.org/10.1016/j.soildyn.2013.02.014, 50, 2013.

[31] S.A. Mitoulis, I.A. Tegos, Reduction of inertial seismic forces in bridges by using the abutment backwall as a "yielding" stopper" Proc., Earthquake Resistant Engineering Structures (ERES), Skiathos, Greece, Chapter V, 507-520, 2005.

[32] EN 1998-2:2005. Eurocode 8: Design of structures for earthquake resistance, Part 2: Bridges, 2005. 